\title{
DEVELOPING PRACTICAL RECOMMENDATIONS FOR SUPERVISORS OF INTERNATIONAL ORGANIZATIONS
}

\author{
Erdem ERCIYES, PhD \\ The MINUJUSTH, The United Nations, Port au Prince-Haiti,(erdemerciyes@yahoo.com)
}

\begin{abstract}
This work investigates leadership concept in the settings of international organizations. Twenty-two semi-structured interviews with supervisors, four focus group sessions with participation of 22 staffs and four non-participant observations with a three-day working schedule was conducted in the World Trade Organization, the International Trade Centre, the United Nations Conference on Trade and Development, and the World Health Organization, in Geneva-Switzerland. Regarding leadership concept, a combination of the GLOBE study, the Implicit Leadership Theory and Schein's leadership approaches, was implemented for the first time in the existing literature in the context of international organizations. Finally, this research brought some practical recommendations for each of the separate International Organizations.
\end{abstract}

Keywords: International Management, Leadership, International Organizations.

\section{ULUSLARARASI ORGANIZASYON YÖNETİCILERİ İÇIN BAZI PRATIK ÖNERILER}

\section{ÖZET}

Bu çalışma, uluslararası organizasyonlardaki liderlik kavramını araştırmaktadır. Dünya Ticaret Örgütü, Uluslararası Ticaret Merkezi, Birleşmiş Milletler Ticaret ve Kalkınma Konferansı ve Dünya Sağlık Örgütünün Ísviçre-Cenevre'deki karargâhının 22 yöneticisiyle yarı yapılandırılmış mülakat, 22 çalışanının katılımıyla dört odak grup çalışması ve her bir organizasyonda üçer günlük katılımcı olmayan gözlemler icra edilmiştir. Liderlik konseptiyle ilgili olarak ilk defa hâlihazırdaki literatüre GLOBE çalışması, örtük liderlik teorisi ve Schein liderlik yaklaşımının birleşimi uluslararası organizasyonlara uygulanmıştır. Sonuç olarak uluslararası organizasyon yöneticileri için uygulamaya yönelik bazı yönetimsel öneriler getirilmiştir.

Anahtar Kelimeler: Uluslararası Yönetim, Liderlik, Uluslararası Organizasyonlar. 


\section{Introduction}

Cultural aspects are fundamental elements of leadership in international organizations (IOs) because leadership qualities are not isolated from the society and nation in which the leader originates from. Cultural characteristics of leader reflect on the relationship of leaders and followers (Hofstede, 1980). In this century, management of a multicultural workforce has mostly been a complementary component of cross-cultural leadership literature. Herein, the GLOBE study (House et al., 2004) gains more importance because it aims to develop an Implicit Leadership Theory (ILT) that is based on cross-cultural understandings with largescale research projects. Thanks to its framework, which takes into consideration different cultural backgrounds, the findings of this research may seem pretty applicable in the context of IOs.

Leadership theory is investigated according to leadership types set out by the GLOBE study, ILT, and Schein's (2004) understanding of leadership and culture. Hence, defining effective leadership gains importance. After determining specific definitions of an effective leader, types of leadership will be further explored in this research through utilizing semistructured interviews, focus group and observations.

\section{Leadership in IOs}

IOs are seen as an important component of public management. As inevitable consequence of this relationship, the progress in public management literature directly influences the leadership concept in the context of IOs. Specifically, the New Public Management (NPM) approach holds an important place in this development. As a response to the economic crises of the 1970s, dominant capitalist states, such as the US and the UK, began to embrace the economic principles of neo-liberalism, and as a consequence of this policy, while free market economy and international financial organizations gained more power, the role of states became less tangible in the global economy (Haque, 2004). This radical shift in the economic policies of the US and the UK also reflected to their public administration management. Moreover, other states were also rapidly influenced by this development and chose to adapt private sector principles such as functional rationality, cost-effectiveness, maximization of real and perceived efficiency and productivity - into their public sectors (Skalen, 2004; Williams \& Lewis, 2008), and thus an NPM concept was put into practice. IOs such as the World Bank, the International Monetary Fund, the WTO, and United Nations Development Programme, supported the globalization of the NPM, especially in developing countries (Haque, 2004). In this context, the concept of "good governance" gained importance and was seen as a complementary part of the NPM approach.

The World Bank was the first entity to utilize the term good governance, as a policy lexicon in a report regarding sustainable growth of Sub-Saharan Africa, in 1989 (Doeveren, 2011). According to this report, due to the failure of public organizations, economic development of Sub-Saharan Africa did not culminate into sustainable development and democracy. As a solution, the World Bank recommended to utilize "the combination of private sector initiative and market mechanisms with good governance which refers to a public service that is efficient, a judicial system that is reliable and administration that is accountable to its public" (World 
Bank, 1989: xii). There is no one definition of "good governance", but it can be defined as a public policy which is based on a set of principles, such as, transparency, accountability and participation (Woods, 2000). Doeveren (2011) explicates that four events triggered the rise of good governance in the world: (1) The end of the Cold War through diminishing the support for authoritarian communist and non-communist regimes; (2) Many authoritarian regimes accepted the principles of "good governance" in return for developmental aid; (3) IOs gained more influence in developing and non-developed countries with their support for developmental policies; and, (4) Humanitarian intervention in countries which violate the right of life, such as Rwanda and Somalia, became an obligation.

The definition of good governance has different meanings in deontological and teleological schools of thought. From the deontological perspective, the concept of good governance has moral foundations based on the Kantian notion of categorical imperative. Universal goodwill lays at the heart of this concept that leads to morally right actions. Goodness is not oriented to results but seen as a virtue of being good in every performed act (Howell, 2000). On the other hand, Machiavellian teleological understanding of good governance is rather different than Kantian notions. Here, goodness is dependent on results and the good in good governance would imply as long as it keeps the ruler in power. IOs, especially the UN, followed the Kantian approach: while UN organizations were encouraging the settlement of these principles, underdeveloped and developing countries also adapted them into their structures. During his tenure, former UN Secretary-General Kofi Annan placed "good governance" principles at the centre of UN reform movements (Missoni \& Alesani, 2014). Annan (1998) sees "good governance" as "the single most important factor in eradicating poverty and promoting development" and defines it as "the rule of law, effective state institutions, transparency and accountability in the management of public affairs, respect for human rights and participation of all citizens in the decisions that affect their lives" (Annan, 2000: 22). This good-governance-centric reform movement was not only limited to UN organizations, but other IOs also embraced its principles of participation, transparency, accountability, and fairness, in their management philosophy (Ngaire, 1999). This reform process encourages two leadership types in IOs: First, changes in organizations, strategic vision, innovation, adaptability, encouraging teamwork, building good communications, and sincere relationships with staff, are seen as important values of leadership (These values associate with transformational and charismatic value-based leadership types) (Prewitt et al., 2011; Thorn, 2012); Second, good governance principles strengthen more participatory management approaches which lead democratic leadership types for IO managers (Ngaire, 1999).

On the other hand, Chevrier (2003) examines cross-cultural management in multinational project groups by conducting a comparative study of three international project groupings. One of the important findings of her research was that tolerance and self-control could contribute to multinational team effectiveness. Another relevant finding of her study was that if team members were well acquainted with each other, they could better cope with existing cultural differences. Finally, she pointed out that if the leaders of an international team at question could not succeed in managing different cultural groups, they could instead build a common team culture. According to Lewis (2006), team culture must be based on building mutual trust in an international group, because trust is a universal term that is current in all cultures and absence of it makes all employees feel unmotivated in their work environment. 
In order to manage cultural diversity effectively, Earley \& Ang (2003) developed the concept of cultural intelligence. Earley (2002: 274) defined cultural intelligence as " $a$ person's capability to adapt effectively to new cultural contexts and it has both process and content features". There are three dimensions in cultural intelligence: a. Cognitive (self-knowledge of understanding cultural similarities and differences) and Meta-cognitive (self-awareness of interactions with different cultures); b. Motivational (self-capacity and drive of adaptation to new cultural circumstances); and, c. Behavioural (self-capacity of showing verbal and nonverbal behaviours during interaction with different cultures). Many scholars accepted cultural intelligence as an inseparable part of cross-cultural leadership and management (Johnson et al., 2006; Templer et al., 2006; Ang et al., 2007; Chen et al., 2012; Morrell et al., 2013; Christiansen \& Sezerel, 2013). Additionally, because of their capacity of understanding different cultures, it may be assumed that leaders who have high cultural intelligence may manage their team members, or staff, in their IOs more effectively.

\section{Methods}

This study investigates leadership concepts in the scope of IOs. In order to grasp depth and different perspectives, three qualitative methods were used: Semi-structured interviews, focus groups, and, non-participant observations. The empirical part of the research was conducted at the WTO, the UNCTAD, the ITC, and the WHO, all of which are headquartered in Geneva, Switzerland. Participants were selected from supervisors and staff of these organizations by utilizing quota sampling techniques (twenty-two supervisors and twenty-two staff). The anonymity and privacy of participants were kept in strict confidentiality: no names or personal information were divulged at any phase of the study, or afterwards. In addition, research participation was based on the volunteerism principle and participants were informed that they would be free to withdraw at any time, if they desired so. Furthermore, before the interviews, protocols and consent forms were provided to them.

In order to grasp different cultural perspectives, GLOBE study's main cultural cluster framework was taken into consideration and participants from different clusters ${ }^{1}$ were encouraged to take part in this research. This act was based on the main assumption that nations which were in the same cluster show similar cultural characteristics and participants represent the main cultural traits of their nations. Furthermore, the participant managers hold different ranks and manage a different number of staff. For example, most are P4, P5, D1 and D2 levels: while a P4 level manager may manage ten workers, a P5 level might manage no one, or two P4 levels with the same title of team-leader could manage totally different numbers of staff members. For this reason, the researcher decided to use the term supervisor in lieu of manager. Also, according to the number of managed staff members, supervisor levels have

1 There are ten GLOBE Cultural Clusters: a. Anglo Cultures: Australia, England, Ireland, New Zealand, South

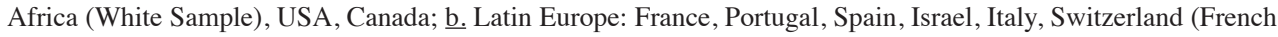
Speaking); c. Nordic Europe: Finland, Sweden, Denmark; d. Germanic Europe: Austria, Germany, Netherlands, Switzerland (German speaking); e. Southern Asia: India, Indonesia, Iran, Malaysia, Philippines, Thailand; $\underline{\mathrm{f}}$. Eastern Europe: Greece, Russia, Albania, Georgia, Hungary, Kazakhstan, Poland, Slovenia; g. Latin America: Argentina, Colombia, Mexico, Bolivia, Brazil, Costa Rica, Ecuador, el Salvador, Guatemala, Venezuela; $\underline{\text { h. Sub- }}$ Saharan Africa: South Africa (Black Sample), Namibia, Nigeria, Zambia, Zimbabwe; i. Middle East/Arab: Turkey, Egypt, Kuwait, Morocco, Qatar; and, j. Confucian Asia: China, Hong Kong, Singapore, Japan, South Korea, Taiwan (House et al., 2004). 
been differentiated, as senior, middle, and junior. Depending on the size of each organization, either five or six supervisors were involved in this research process.

Non-participant observations were performed in the four IOS. The officials of the IOs were informed with a protocol before observations and the researcher followed their three-day working schedules. During observations, the researcher focused on limited areas and described what he saw and felt concerning definition of ILT's effective leadership ${ }^{2}$, GLOBE study's leadership types ${ }^{3}$ and Schein's leadership and organizational culture model $^{4}$.

\section{Findings and Interpretation}

\subsection{The World Trade Organization $(\text { WTO })^{5}$}

Firstly, supervisors' definition of effective leadership was explored in the interviews. According to the supervisors, the main effective leadership characteristics are being inspirational, persuasive, motivational, visionary, fair, trustworthy, knowledgeable, nice, a good example, having the ability to set directions, pushing staff for that extra mile, having integrity, and communicating effectively. Furthermore, one of the participants put an emphasis on sharing information with team members. On the other hand, when the staff debated in the focus group discussion, they emphasized the role of communication, especially the ability of communicating with different levels and staff members. In addition, the leader must communicate clearly and be able to motivate the staff by this means. The second stated leadership characteristic was to be able to provide a vision that would help keep the staff on the right path. The third characteristic, as one participant aptly noted, referred to the aspect of decision-making:

"...a decision maker for me, that is something very key, somebody who can take a decision and somebody who knows exactly what needs to be done."

Yet one other participant believed that this decision-making ability must be carried out in a fair manner:

"For me fairness, I agree with all this, fairness is very important, I think I would rather have a boss who I think is fair. Such that, I feel that whatever good happens through the workplace, that it is to be distributed in a fair fashion, I do not have to worry about it. I do not

2 ILT infers that culture, social environment, and individual characteristics have impacts on definition of effective leadership and it may vary in manifold societies (Lord \& Maher, 1991).

3 The GLOBE study developed its own culturally endorsed ILT that is composed of six leadership dimensions: a. the charismatic/value-based; b. the team-oriented; c. the participative; d. the humane-oriented; e. the autonomous; and, f. the self-protective (and group-protective) (House et al., 2004).

4 Schein (2004) infers that at the beginning, leaders create culture then, if followers accept and embrace this culture, the successor of the leader can be chosen according to the culture. In addition, Schein described three culture levels: a. Artifacts, b. Espoused Values, and, c. Basic Underlying Assumptions. Organizational culture of the IOs is scrutinized basing on the levels.

5 The WTO is an IO, which aims to regulate global trade rules amongst countries by utilizing the following methods: supervising trade agreements; serving as a negotiation forum; helping settle disputes; providing technical assistance and training programmes for developing countries; and cooperating with IOs and NGOs. In lieu of the General Agreement on Tariffs and Trade (GATT), it came into force in Geneva, Switzerland, in 1995. Its decisions are necessarily taken by the unanimous support of all 162 member states, and their approval. 
have to lobby to get my share of that. I have to be confident about that and I could focus on my work."

In addition, honesty, being able to think strategically, driving the mission, and taking responsibility for one's decisions no matter what the outcome, were other characteristics seen as necessary for an effective leader.

As the supervisors defined effective leadership, they mostly leaned towards the charismatic/value-based leadership characteristics, such as being inspirational, visionary, a good example, etcetera. On the other hand, one of the participants encouraged a team-oriented style by placing emphasis on sharing information with team members. When the staff defined an effective leader, they placed emphasis on having the ability to communicate well, think strategically, and have vision and honesty, be a good decision maker, have a sense of fairness, and take responsibility for one's decisions. Overall, it can be concluded that these characteristics define the charismatic/value-based leadership style.

Apart from the findings of the interviews and focus groups, the observation results show the tendency of supervisors having the participative style of leadership. For example, consensus is the main decision-making tool among member states of the WTO. Each country has the power to block the decision of the other 160 . To this effect, the supervisors hold a facilitator role in the discussions and try to find a middle ground among member states. In this context, the ability to negotiate, coordinate, and conciliate, are seen as important values for the supervisors. These values also reflect upon their relationship with the staff. During their discussions, the supervisors did not seem stubborn about their opinions, and in lieu of direct rejection of an idea, listened and tried to convince them in the desire to reach consensus. They kept open communication channels, showed respect to staff opinions, tried to find a middle ground, and worked for their consent.

\subsection{The United Nations Conference on Trade and Development (UNCTAD) ${ }^{6}$}

Supervisors defined effective leadership in the interviews, as, desirable to be followed, setting an example, honesty, confidence, being respected, thoughtfulness, fairness, discreetness, succinctness, and being results-based and team-oriented. Likewise, focus group discussion was also focused on the same subject. According to staff, the characteristics of an effective leader are found in: being reliable; a role model; having organizational abilities; delegating and using human capital; establishing a balance between greater and collective good; being aware of followers' needs; being clear, approachable and charming; understanding resource issues; and understanding the constraints, and also the weakness and strengths, of staff. Furthermore, it was observed that there was a mechanics and a level of professional relations amongst supervisors and staff, and even amongst colleagues. When staff prepared a draft paper, it was sent through the intranet system and their supervisors and related personnel could see and add

6 The UNCTAD was founded in 1964 as the main UN body concerned with trade and development issues. The focus of the organization are globalization and development, trade and commodities, investment and enterprise, economic progress of developing and least developed countries, technology, and logistics. The organization is responsible to its 193-member states for developing macroeconomic policies for the purpose of ending global economic inequalities and encouraging people-centric sustainable development. Its main work motto is, "think, debate and deliver." 
their comments. After receiving the final version, it would be sent by email to the supervisor. When a task was accomplished, they just moved on to the next step. Apart from that, there was no noticeable face to face feedback between the supervisors and the workforce.

While the participants described effective leadership, they specified the main traits and behaviours of charismatic/value-based and team-oriented leadership styles, such as, being inspirational and a role model, having integrity, and being performance and team-oriented. On the other hand, during observations, it was realized that there was an obvious communication problem between supervisors and staff, which connoted a mechanical relationship. In lieu of performance concerns, the supervisors had a professionalism concern. They define tasks via electronic mail and expect everything to be prepared by their staff without providing any face to face feedback to them. The attitude of the supervisors was very far off from the idealized effective leadership styles explicated by the participants.

\subsection{The International Trade Centre $(\text { ITC })^{7}$}

The supervisors defined effective leadership in the interviews, as, being accessible, visionary, inspirational, able to manage at a macro-level, enhance skill sets of the staff, resultoriented, having technical capabilities, show love, care, honesty, fairness, justice, ensuring team spirit, and not abusing power. While defining effective leadership, four types were highlighted by them: charismatic/value based; team oriented; human oriented; and, participative. Instead, both transformational and charismatic leadership types were perceived equivalent to effective leadership by the staff. They enumerated being able to amalgamate skills and abilities, such as being smart and efficient, making people listen and work together, being an example and able to deliver a vision and objectives, transforming the organization, communicating efficiently, obtaining desired resources, and having certain personal qualities and charisma, as the main characteristics of an effective leader. In addition, the staff inferred that they already had team spirit at their division, thanks to the cooperative-collaborative work environment, but they and other participants posited that the main actor who provided this environment was the "leader":

" $C$ : Why do we need to create team spirit? I feel that we have already team spirit. I am new in the team, there is already a sort of collaboration and cooperation, I think the match is good in the team. There is already something there. What should be we created? I think type of personality maybe type of manager created this atmosphere.

B: Of course, type of personality differences a lot. But more important is when you have a good leader or good manager that, the team was totally different

A: ... The spirit is there. We just go and do it together. But also, boss influences and ables that."

7 In order to support the WTO's rules of trade, and the UNCTAD's research and policy strategies, the ITC as an international organization was established in 1964. Its main goals are to support economies of developing countries in their integration into the global economy, advance capacity of trade and investment support of institutions for the sake of Small-Medium Enterprises, and enhance their competitiveness. Regarding management issues, the head of the ITC reports to the Secretary General of UNCTAD and the Director General of the WTO and the Joint Advisory Group which is embodied by their organizations' supervision of ITC actions. 
Herein, we can conclude that the staff expect from their supervisors to be leaders who are not just managing given projects but are also visionary and inspirational and can contribute to team collectivism. Furthermore, during observations, two types of desired leadership styles were observed, as, charismatic/value based and participative. When staff prepared the first draft of any work, they sent it to their supervisors with an email. Afterwards, the superior received a printed copy of that document on which he could make additions, augmentations, and amendments, usually with colour pens. If it became necessary to orally communicate with someone, they were usually contacted by telephone. Thereby any changes could be implemented in this manner. When staff disagreed, or required further clarifications, they usually met interactively. Supervisors could listen to every idea and attempted to assist staff by various means. Instead of giving an order and then withdrawing into one's own ivory tower, the supervisors tried to convince their staff by sharing information and holding interactive discussions. They relied on their knowledge but show respect for staff opinions as well.

\subsection{The World Health Organization $(\mathrm{WHO})^{8}$}

While defining the main effective leadership characteristics, the supervisors highlighted some of the attributes of the charismatic/value based leadership style, such as being visionary, having the ability to motivate, sharing accolades, facilitating discussions, showing respect, providing transparency, demonstrating cultural sensitivity, being non-threatening, having smarts, and being fair. In addition, they placed much importance on being able to understand staff's values, develop tailored-based management for each individual, and empowerment as regards the individual values of each member. On the other hand, according to the staff, being a role model was an important attribute of effective leadership:

"D: The ability to gather people around an idea or a project.

B: Trust and motivation I would say. Definitely to get their trust and make people do something even when they do not almost want to do it. But I would not know which one to choose because I would not go with any of those on how I would pick a leader. The one I aspire to is also the one I would want to be. Like a role model. Why I would choose him.

\section{F: I think an effective leader is someone who takes responsibility.}

E: Someone who has the ability to gather people around an idea. Is capable of taking responsibility and someone who is willing to go the extra mile just to show the others the right path and who leads by example.

C: Exactly. That is the first thing for me. A good leader is one who leads by example. It is not one that commands but actually does. He leads by example. He shows how to do things. He is skilled in what he does and knowledgeable. So, the leader basically should be knowledgeable and skilled in whatever he does. He leads by example and can build trust in his team. For me that is an effective leader in any area."

8 As a specialized agency of the UN, the WHO was established on 07 April 1948 in Geneva. It is the authority at the head of the international health system within the UN by providing leadership on critical health issues, advancing knowledge, shaping the research agenda, framing norms and standards, establishing ethical and evidence-based health approaches, providing technical support for underdeveloped and developing countries, and monitoring health matters all over the world. 
Moreover, during department meetings, the Director placed importance on sharing information and raising the level of awareness at events and occurrences. To this effect, he also illustrated that providing coordination between the teams is an important asset of his leadership approach.

\section{Comparison of IOs}

This research into leadership understanding leans heavily on ILT in which the individual's perception and belief of effective leadership gains importance. When we think of broad diversification of the workforce at IOs, the accumulation of individual opinions and their intersection provide an idea about common effective leadership traits at these institutions. To this effect, the explicated views of leadership qualities are mainly based on how participants have defined effective leadership themselves, and from the researcher's observations. The common characteristics of effective leadership enumerated by the participants of all the organizations are as follows: having vision, being fair and accessible, being a good communicator, demonstrating respect towards others, and, being able to motivate in pursuit of necessary objectives. Surprisingly, although IOs have their nature rooted in multiculturalism, apart from the WHO participants, the others did not value demonstration of cultural sensitivity as an attribute of an effective leader. The supervisors and staff of the WHO have more field work than the staff of the other three organizations. In these field works, due to dealing with diversified nationalities, they may well understand the importance of cultural sensitivity. To this effect, the leaders of the WHO must have the capability of working effectively across cultures more than the other organizations' leaders.

Even though different types of leadership were identified by the participants, the charismatic/value-based type was the intersection point for all of them. This finding is also related to power perception of the participants. In order to accept a leader as a power figure, and be influenced by him/her, they desire to see divinely conferred talent, vision, emotional intelligence, trustworthiness and self-monitoring. As well, the only organization which encouraged transformational leadership was the ITC. This finding may be explained by the focal point of ITC's mission and goals. Since the ITC's main focus is on transforming and adapting the SMEs of developing countries into the global economy, hence, transformational leadership fits best for this context.

\section{Practical Recommendations}

Even though this design enriches the research process and provides an in-depth understanding of the research topic, it places an important limitation, that of generalization of findings. Instead of generalization, transferability criterion was utilized in the research. Hence, the findings cannot be generalized but they can be transferred to similar situations.

\subsection{For Supervisors of the WTO}

The sensitivity of officials regarding social responsibility, such as, providing facilities for the disabled, a library, a meditation room, a health care service, maintaining green foliage, and presentation of artworks, is well reflected in the observations of the staff; they give the impression of being rather happy to be part of a pleasant environment. On the other hand, one 
of the basic underlying assumptions for the staff is that, "there was not much room for being creative". In order to provide a more creative environment, after defining the main tasks, details of a given work should be determined by the staff and more initiative should be encouraged by officials and supervisors.

When we look at staff profiles, it can be seen that they have graduated from prestigious universities and have had remarkable careers and work experience, in either the private or public sectors. For these types of people, as inferred by McClelland (1961), the power need is satisfied in the axis of recognition over having a bigger office or a private printer. Therefore, they view promotion as an individual recognition of their achievements by their superiors, and in so doing, winning the competition over other colleagues. Hence, the organization should establish career development programmes, and provide more promotional opportunities.

In order to demonstrate a more effective leadership style at the organization, the supervisors should be inspirational, persuasive, visionary, fair, trustworthy, knowledgeable, pleasant, and set a good example (Lord \& Maher, 1991). They must also have the ability to provide direction, demonstrate integrity, push staff for the extra mile, communicate effectively, share information with team members, be able to think strategically, drive the mission, take responsibility no matter what the outcome, show respect, find a middle ground in discussions, and get the consent of their workforce.

While motivating staff, in lieu of focusing on disparate national cultures, international cultural entities should be understood by focusing on values, beliefs, assumptions, rituals, and symbols (Schein, 2004). Likewise, in order to provide better motivation, supervisors should focus on non-monetary tools, such as, rendering appreciation through explicitly highlighting achievements, imparting responsibility and autonomy, emphasising PSM, setting greater challenges, according greater responsibilities, and reducing bureaucracy. In addition, they should abstain from dispensing negative feedback and boring duties, accommodating a lack of communication, limiting promotion opportunities, and ignoring the achievements and existence of the staff.

\subsection{For Supervisors of the UNCTAD}

Participants emphasised the negative role played by dull bureaucracies, especially when attempting change and developing the work atmosphere. In order to reduce this effect, officials should establish a more flexible reporting system, delegate authority, reduce hierarchical standings, and encourage horizontal interaction rather than vertical hierarchy. Similarly, supervisors should share more information with their staff and trust responsibilities to them. In addition, the office atmosphere should be made livelier.

There is an obvious communication problem in the organization. In lieu of email and phone, more face-to-face contact should be established between supervisors and staff. In addition, social activities, at work and out of work, should be organized, and an open-door policy be put into practice. On the other hand, newcomers are not welcomed easily by senior staff members; hence, an orientation programme should be established for newcomers where they should also be introduced to senior staff members. 
One of the basic underlying assumptions in the organization is that: "There are two types of staff: professionals and others". This is the biggest obstacle as regarding staff motivation, and the main reason for losing qualified workers. In order to remove it, firstly, officials should provide more long-term contract opportunities. In addition, staff opinions should be frequently and considered in the decision-making processes. Some professional privileges, such as, educational grants, early retirement opportunities, longer holidays, and training, should be provided to other staff as well.

In lieu of pursuing autocratic leadership behaviours, such as, placing communication barriers between themselves and their staff, not sharing power or authority, and discouraging staff participation in decision-making processes, supervisors and officials should show charismatic/value-based and team-oriented leadership styles (Lord \& Maher, 1991). Some of the main characteristics of these leadership styles, such as, establishing a vision which can be followed by participants, taking staff opinion into consideration in the decision-making process, building team spirit, giving out more authority and responsibility to staff, are appropriate and advantageous here.

There is a motivation problem, which may be the source of other problems in the organization. Thus, officials should urgently focus on this issue. As a starting point, participants do not believe that nationality makes an impact on their motivation levels. Motivational expectations develop as non-monetary motivational tools, such as, limiting bureaucracy, setting more challenges, having higher responsibilities, providing opportunities, increasing promotion options, recognizing achievements, matching staff abilities with appropriate jobs, team building exercises, providing positive feedback and a feeling of involvement, defining a clear vision, and establishing communication. Alternatively, officials and supervisors should avoid limiting vacant posts, restricting flexible work hours, neglecting staff, assigning more work than capacity, issuing boring orders and negative feedback, and limiting communication channels. From theoretical perspective, McClelland's (1961) motivation theory can be a good starting point to solve the problems.

\subsection{For Supervisors of the ITC}

The organization has an open-door policy; this policy is well-reflected in the working habits of participants through the provision of a relaxed interactive environment and assistance in the establishment of positive group dynamics. However, some of the supervisors and staff unintentionally have the tendency to impose on this by dominating discussions and imposing their own beliefs and values on others. Thereby, officials and supervisors should be more careful when conducting group discussions, and pay attention to all voices and opinions. Additionally, informal-apparel-day implementation is not only providing a relaxed work environment, but it is also displaying organizational awareness towards individual existence. Hence, officials should maintain its implementation.

An understanding of hard power is common among participants, such as, valuing hierarchy, being able to use financial resources, authorizing decisions, and controlling others. This understanding also led to high power distance (House et al., 2004). In order to reduce this distance, officials and supervisors should follow a more participatory approach in the 
process of decision-making. Moreover, according to the participants, officials should provide long-term contracts. Apart from this, their motivational expectations are about non-monetary tools. Officials and supervisors should encourage the idea of working for the common good, providing training, allocating responsibility, minimizing interference in staff duties, starting new projects, showing respect for individuals' plans, creating an environment that provides an equal voice for all, strengthening recognition of the organization, delegating, demonstrating care and trust, providing good leadership, providing more promotional opportunities, allowing for work and life balance, and acknowledging good deeds with good words. Contrariwise, they should not set unexplained tasks, take all the credit for themselves, restrict promotion opportunities, impede opinions, give boring tasks, and present false hope.

\subsection{For Supervisors of the WHO}

The WHO successfully reflects its global health care mission onto the organization. This approach is rather effective at reminding staff members of the existential reasons of the organization. What is more, staff also feel valuable when seeing this kind of staff-centric implementation. However, during meetings with externals, more seating spaces should be provided for staff in order to make them feel included, and not excluded, by officials.

There is an obvious communication problem at the organization. The staff immured themselves within invisible walls and hindered the flow of verbal communication. In order to improve communication, supervisors should arrange face-to face meetings more often, administer clear tasks, avoid personalizing work problems, demonstrate more empathy, and be accessible. In addition, while the participants defined effective leadership, they placed special importance on being a role model. Officials and supervisors should be aware of this expectation and pay more attention to their behaviours.

Furthermore, in order to increase motivation at the organization, officials and supervisor should establish a well-designed appraisal systems, display clear leadership guidance, acknowledge followers, provide more promotion options, ascertain that human resource staff come from the field, build team spirit, share a vision, allow for everybody's contribution, develop individualized motivation systems, recognize individuality, permit attendance at international conferences, afford travel opportunities, sanction more responsibility for staff, hire more motivated workers, face new challenges, establish a learning environment, reduce bureaucracy, provide more flexibility, encourage new ideas, establish an efficient performance system, make certain of fairness in all organizational decisions, show respect, and increase awareness of staff PSM. In contrast, they should avoid giving negative feedback, especially publicly, and not say a simple thank for achievements, establish open conflict environment at the workplace, demand consistency, impose drudgeries, and ignore staff motivation levels.

\section{Conclusion}

While the findings of interviews and focus group forward the charismatic/value-based leadership style, the observation results indicate the participative style of leadership. We can infer that combination of both leadership types can be effective in the WTO. There is an important contrast between staff's effective leadership expectations and supervisors' behaviours in the UNCTAD. While charismatic/value based and team oriented leadership styles are 
preferred by the staff, supervisors mostly show characteristics of autocratic leadership such as cutting verbal communication with their staff through developing more mechanic superior and subordinate relationship and discouraging staff's participation to the decision-making process. On the other hand, charismatic, value based, transformational, team oriented, human oriented and participative leadership are preferred by the participants of the ITC. However, there is a consensus among participants as charismatic /value based leadership best fits for the definition of effective leadership.

Through the use of the ILT, the definition of an effective leader found more significance. The participants described the main characteristics of an effective leader as: being visionary, fair, accessible, and a good communicator; showing respect towards others; and, being able to motivate staff towards the achievement of an objective. These attributes lead to the finding of a charismatic/value based leader as the most preferred leadership type by participants.

\section{References}

Ang, S., Dyne L. V., Koh, C., Ng, Y. K., Templer, K. J., Tay, C., \& Chandrasekar, A. (2007). Cultural intelligence: Its measurement and effects on cultural judgment and decision making, cultural adaptation and task performance. Management and Organization Review, 3(3), 335-371.

Annan, K. (1998). Report on the work of organization. United Nations Secretariat, New York.

Annan, K. (2000). The role of United Nations in the $21^{\text {st }}$ century. United Nations Department of Public Information, New York.

Chen, X. P., Liu, D., \& Portnoy, R. (2012). A multilevel investigation of motivational cultural intelligence, organizational diversity climate and cultural sales: Evidence from U.S. real estate firms. Journal of Applied Psychology, 97(1), 93-106.

Chevrier, S. (2003). Cross-cultural management in multinational project groups. Journal of World Business, 38, 141-149.

Christiansen, B., \& Sezerel, H. (2013). Diversity management in transcultural organizations. Global Business Perspective, 1(2), 132-143.

Doeveren, V. V. (2011). Rethinking good governance. Public Integrity, 13(4), 01-318.

Earley, P. C., \& Gibson, C. B. (2002). Multinational work teams: A new perspective. Mahwah, NJ: Lawrence Erlbaum.

Earley, P. C., \& Ang, S. (2003). Cultural intelligence: An analysis of individual interactions across cultures. Palo Alto: Stanford University Press.

Haque, M. S. (2004). New public management: Origins, dimensions and critical implications. In K. K. Tummala (Ed.), Public administration and public policy. Oxford: Eolss Publishers Ltd.

Hofstede, G. (1980). Motivation, leadership, and organization: Do American theories apply abroad. Organizational Dynamics, 9(1), 42-63.

House, R. J., Hanges, P. J., Javidan, M., Dorfman, P. W., \& Gupta, V. (2004). Culture, leadership, and organizations: The GLOBE study of 62 societies. California: SAGE Publications. 
Howell, K. E. (2000). Discovering the limits of European integration: Applying grounded theory. New York: Nova Science Publishers.

Johnson, J. P., Lenartowicz, T., \& Apud, S. (2006). Cross cultural competence in international business: Toward a definition and a model. Journal of International Business Studies, 37, 525-543.

Lewis, R. D. (2006). When cultures collide. 3d ed., Boston: Nicholas Brealey International.

Lord, R. G., \& Maher, K. J. (1991). Leadership \& information processing. London: Unwin Hyman.

McClelland, D. C. (1961). The achieving society. Princeton, NJ: Van Nostrand.

Missoni, E. (2014). Transnational hybrid organizations, global public-private partnerships and networks. In E. Missoni and D. Alesani (Eds.), Management of international institutions and NGOs. Oxon: Routledge.

Morrel, D. L., Ravlin, E. C., Ramsey, J. R., \& Ward, A. K. (2013). Past experience, cultural intelligence and satisfaction with international business studies. Journal of Teaching in International Business, 24(1), 31-43.

Ngaire, W. (1999). Good governance in international organizations. Global Governance, $5(1), 1-21$.

Prewitt, J., Weil, R., \& McClure, A. (2011). Developing leadership in global and multi-cultural organizations. International Journal of Business and Social Science, 2(13), 13-20.

Schein, E. H. (2004). Organizational culture and leadership. 3rd ed., San Francisco: JosseyBass Inc.

Skalen, P. (2004). New public management reform and the construction of organizational identities. The International Journal of Public Sector Management, 17(3), 251-263.

Templer, K. J., Tay, C., \& Chandrasekar, N. A. (2006). Motivational cultural intelligence, realistic job preview, realistic living conditions preview and cross-cultural adjustment. Organization Management, 31,154-173.

Thorn, I. M. (2012). Leadership in international organizations: Global leadership competencies. The Psychologist-Manager Journal, 15, 158-163.

Williams, W., \& Lewis, D. (2008). Strategic management tools and public-sector management: The challenge of context specificity. Public Management Review, 10(5), 653-671.

Woods, N. (2000). The challenge of good governance for the IMF and the World Bank themselves. World Development, 28(5), 823-841.

World Bank, (1989). From crisis to sustainable growth- sub-Saharan Africa: A long-term perspective study. Washington DC: The World Bank. 